\title{
Marine geophysical methods for archaeological investigation of volcanic and bradyseismic areas
}

\author{
Francesco Giordano \\ Istituto Universitario Navale, Napoli, Italy
}

\begin{abstract}
The aim of this work was to test several geophysical methods for the identification and study of submerged prehistorical coastlines and archaeological sites. This research program was carried out in collaboration with the «Osservatorio Vesuviano» in the Gulf of Pozzuoli and dealt in particular with the bathymetric strips extending from $-5 \mathrm{~m}$ to $-50 \mathrm{~m}$ Within these strips we identified the coastline dating from the Roman period, former beach boundaries associated with the vertical movements of the earth's surface caused by seismic-volThe UNIBOOM lines and submerged bas used for this part of the programme, permitting the identification of several coastlines and submerged beaches lying at different levels. The use of a modern Side Scan Sonar - for the morphological investigation of the sea bed - in a zone which had been the object of numerous archaeological surveys in the past, permitted previously unknown structures near the Lacuus Baianus to be identified. Other features worth pointing out include the operating speed of the system $\left(15000 \mathrm{~m}^{2} /\right.$ first minute approx $)$ and its observation capacity in cloudy waters compared to visible radiation, as well as its ability to penetrate thin layers of mud which generally impede direct underwater observation.
\end{abstract}

Key words Gulf of Pozzuoli (Naples) - marine archaeology - marine prospections - geophysical methods - marine archaeological survey

\section{The results obtained with the UNIBOOM system}

The UNIBOOM system is a marine acoustical system characterized by a high vertical resolution power supply and high working frequency $400-14000 \mathrm{~Hz}(1 \mathrm{~Hz}=1 \mathrm{cycle} / \mathrm{s})$. Two layers lying $.20 \mathrm{~m}$ apart can be resolved provided that the surface which separates the two layers of different media is visible, i.e. if their acoustical impedences are sufficiently different (Stefanon, 1985a).

The UNIBOOM survey led to the discovery of former submerged beaches and covered coast lines. The area investigated lies to the north-east of the city of Naples and is marked on the map as the Gulf of Pozzuoli (fig. 1). The phenomena we have tried to discover occurred over the past 10000 years, during which time there has been a variation in the sea level of approximately $+100 \mathrm{~m}$ (Pescatore et al., 1984, Luongo et al., 1991). There are several geological-structural maps of the Gulf of Pozzuoli in print, but the most complete one «the morphostructure of the Gulf of Pozzuoli» (1-20000) was drawn up by Segre (Segre, 1972). In the last 25 years the area has been the subject of a variety of important geophysical surveys (reflection seismics), but none of these was carried out along the coastline and none had the same aims as our research. During the months of February and March 1993 we investigated strips of the coastline lying between the 


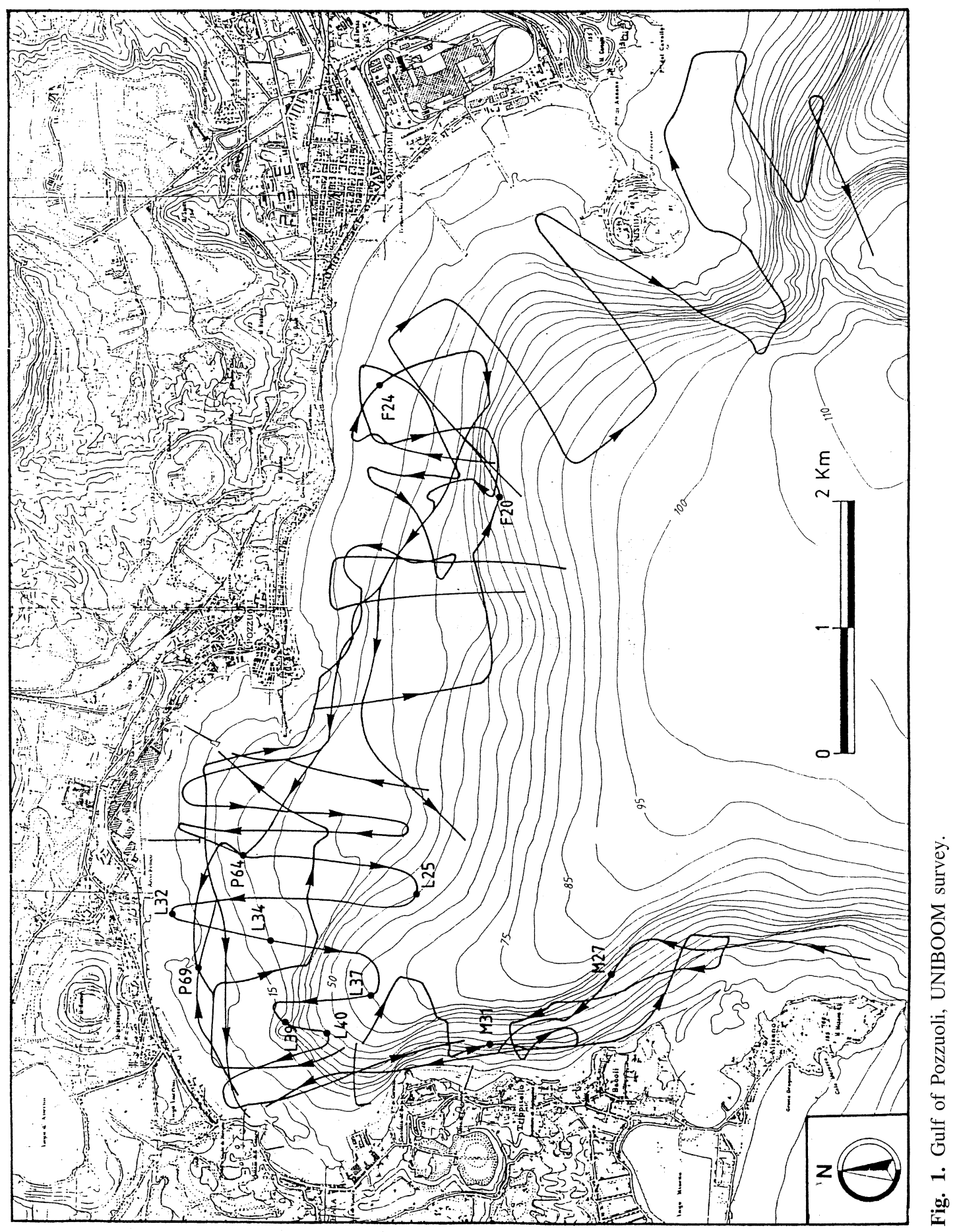


bathymetrics of $5-50 \mathrm{~m}$. Figure 1 shows the navigation route taken. The readings were preceded by numerous trial runs in order to obtain the best results from the measuring equipment, and in particular:

- the signal filters;

- the regulating of the geometry of the transducer-receiver couple of the UNIBOOM system.

When interpreting the data we initially used Segre's map (mentioned above) as a reference for standardization purposes, but later we pro- ceeded independently. The peculiarity of our measurements was due to the following factors:

- the precise positioning of the boat was facilitated by the GPS system; used;

- a small, manageable fishing boat was

- good signal penetration with little reverberation was achieved even in deep water.

Thus we were able to detect:

- areas of marine erosion, which were uncovered or covered by more recent sediments;

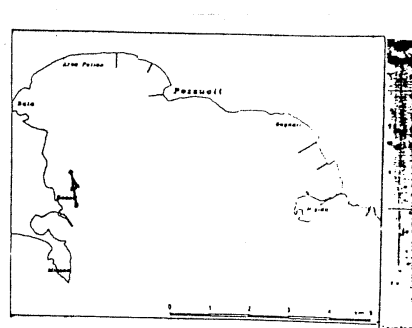

M28 M29

$\begin{array}{lllll}M 27 & M 28 & M 29 & M 30 & M 31\end{array}$

$\begin{array}{lllll}M 27 & M 28 & M 29 & M 30 & M 31\end{array}$
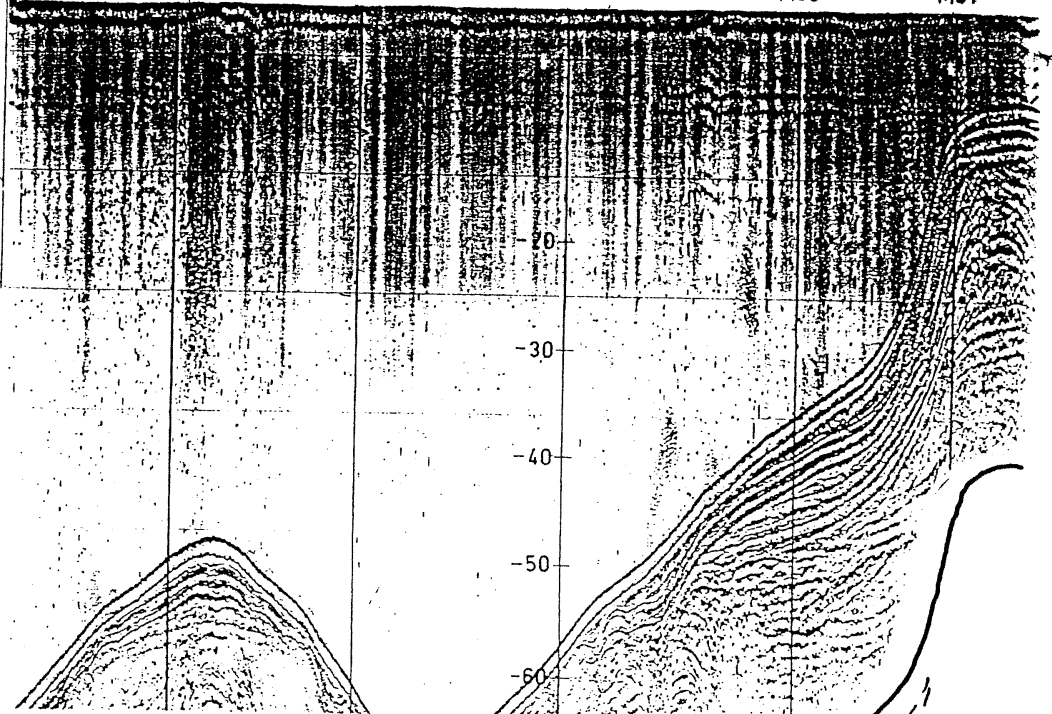

$S=B E A C H$

$E=$ EROSIONAL SURFACE

$D C=$ PEBBL.Y DETRITUS

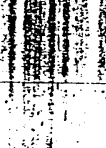

-10
$-\quad-30$

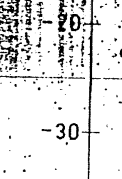

Q
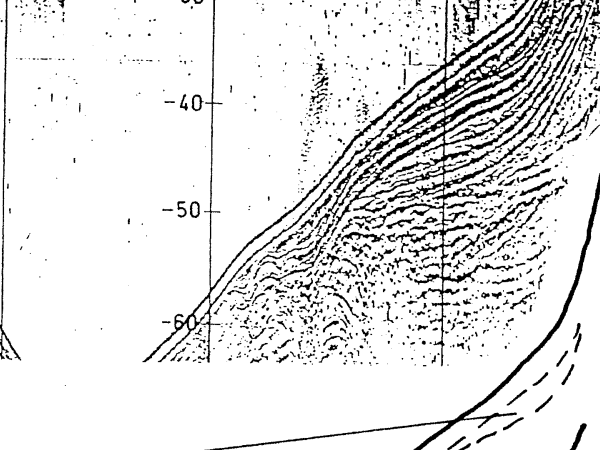

$S \&$

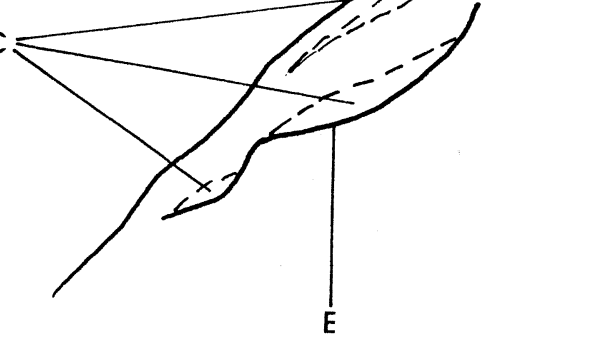

Fig. 2. Stratigraphy of the sea bed in front of the town of Bacoli along the route M27 to M31. An accumulation of detritus $10 \mathrm{~m}$ thick is evident between bathymetrics 40 and 50 . Traces of beach and erosions are also
present. 
these are characterized on the graph recording by the sudden interruption of the sedementary lines;

- former beaches which were superficial or covered, characterized by the presence of pebbles and chaotic material; these were easily recognizable in the recordings.

Further on we will analyse examples of the most important recordings.

The sea bed lying in front of the town of Bacoli (fig. 2) is characterized by the presence of a highly accentuated underwater slope. Along the route from M27 to M31 there is an obvious accumulation of material which is more than $10 \mathrm{~m}$ thick between bathymetrics 40 and 50 in a parallel direction to the map. This recording picked up traces of beaches and slightly accentuated erosions.

Figure 3 shows the route from L35 to L39, including a $180^{\circ}$ change of course at L37. This recording points out a strip of chaotic deposits which is more or less accentuated according to the morphological slant of the main basic horizontal. The maximum thickness of approximately $5-6 \mathrm{~m}$ is reached according to the -60 $\mathrm{m}$ bathymetric.

Another interesting route lay in front of Arco Felice, running almost parallel to the coastline, from P64 to P69 in fig. 4. A stratification which could be correlated to the presence of compact materials of a regular struc-

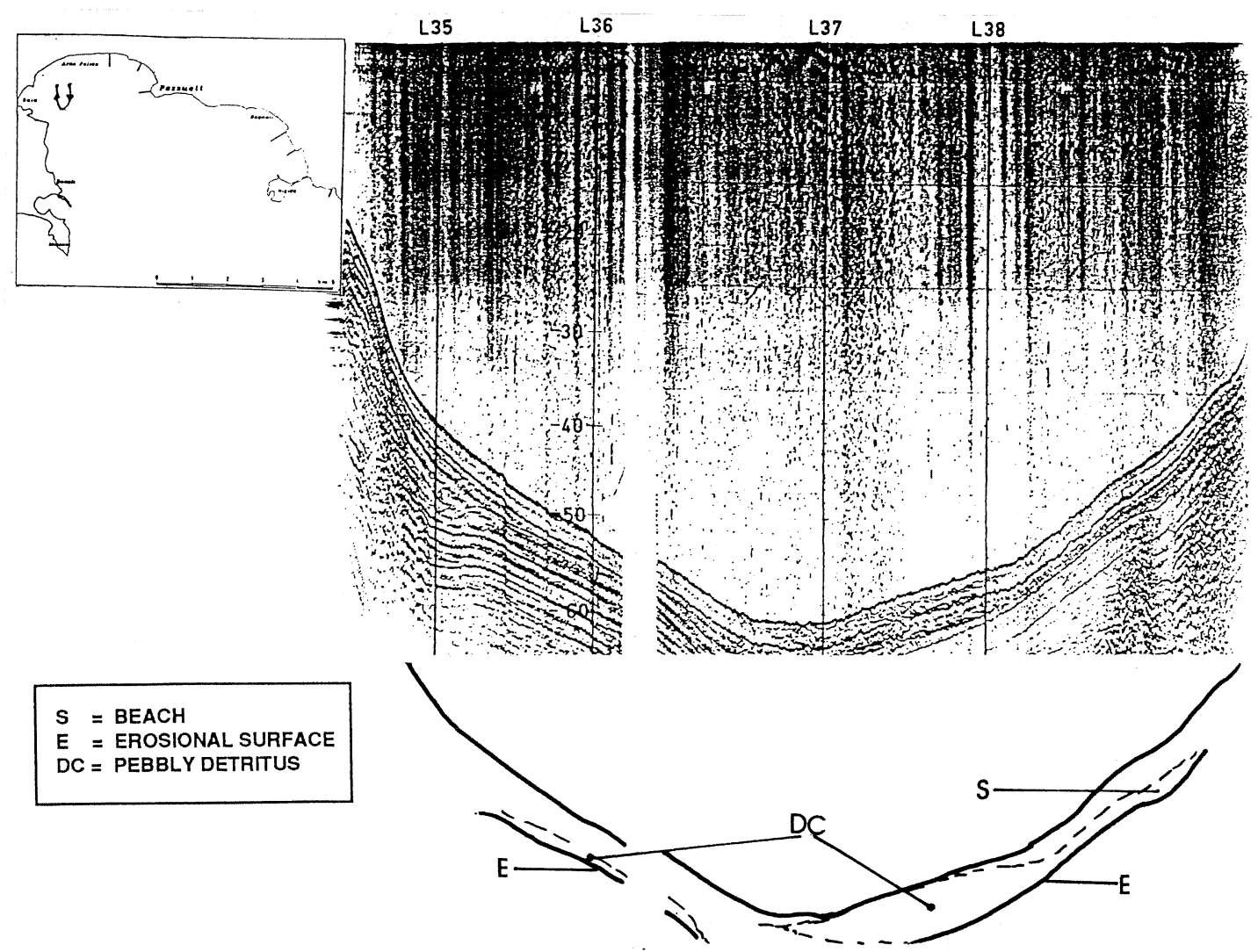

Fig. 3. Route from L35 to L38 with a $180^{\circ}$ change of course in L37; a stratification of chaotic material 5-6 m thick is present. 


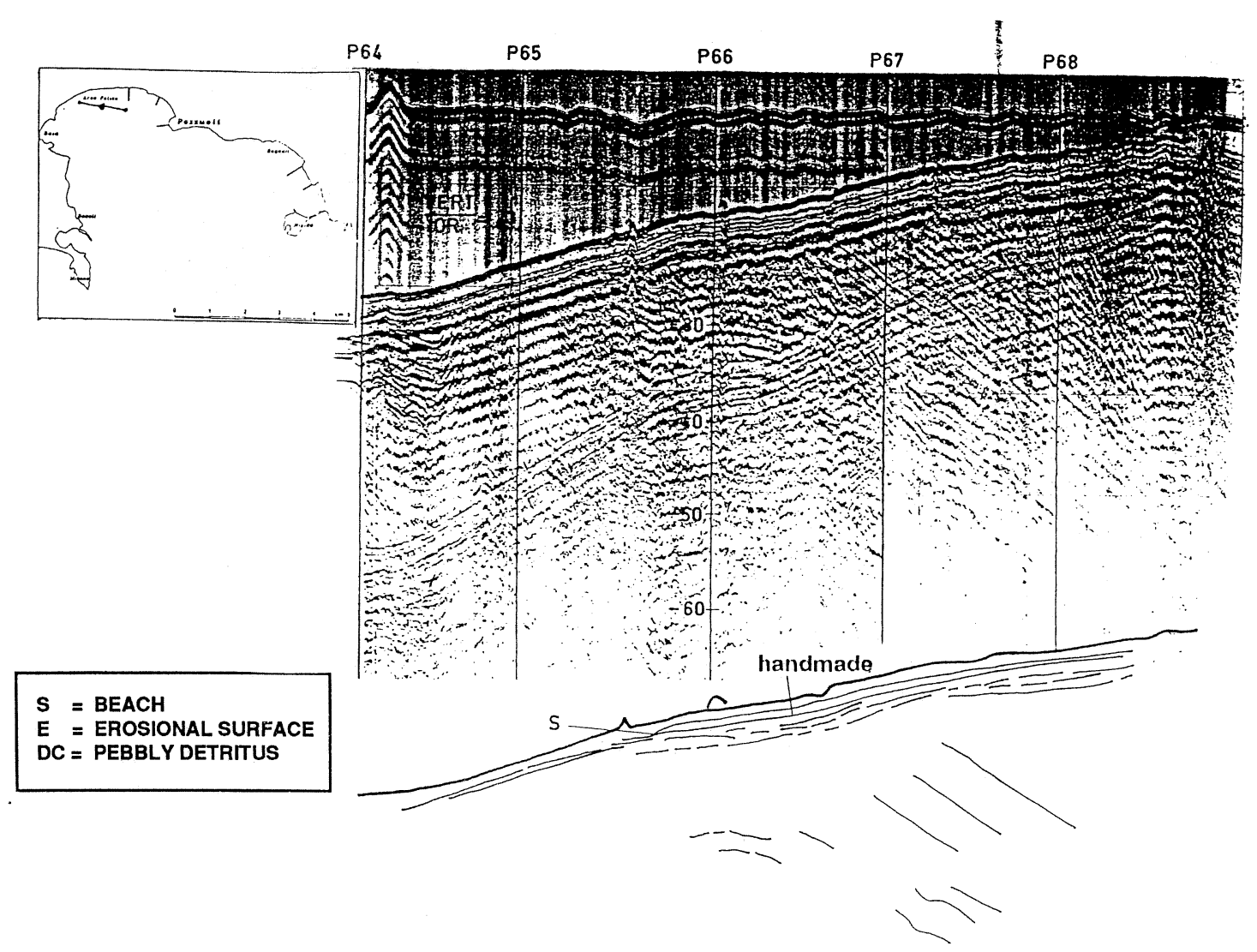

Fig. 4. Route very near the coastline from P64 to P69 in front of the town of Arco Felice; the first horizon is made up of a highly regular stratification, thus suggesting the presence of artificial paving on top of uneven
material.

ture - possibly manufactured - lays above a layer of fairly uneven detritic material.

The route opposite Arco Felice, shown in fig. 5, running south-northwards along L26 to L31 from bathymetric $50 \mathrm{~m}$ to $5 \mathrm{~m}$, contained two examples of terracing (one from $-50 \mathrm{~m}$ to $-40 \mathrm{~m}$, and the other from $-25 \mathrm{~m}$ to $-12 \mathrm{~m}$ ), and traces of covering by material which from the recording appeared pebbly and not very even. This could therefore be correlated to an extended example of underwater beach. The bed-rock (substratum) is present underneath, and has areas where it is missing due to strong absorption by the layers on top, but nonetheless it is easy to follow. Considering that there is a 23 times vertical deformation the slopes, it can be deduced that the slope of each layer is in the region of 1.5-2 degrees, according to bibliographical data (Pescatore et al., 1984). The two detritic masses, one lying at approximately $-20 \mathrm{~m}$ and the other at $-40 \mathrm{~m}$ can respectively be correlated to units C and D of Segre's Map, even though their extensions and positioning do not agree exactly with each other. We will mention this again later.

As can be seen from the navigation map (fig. 1), readings were also taken in the area around the island of Nisida and beyond, but their quality was not sufficient to obtain proper coverage of the area. 


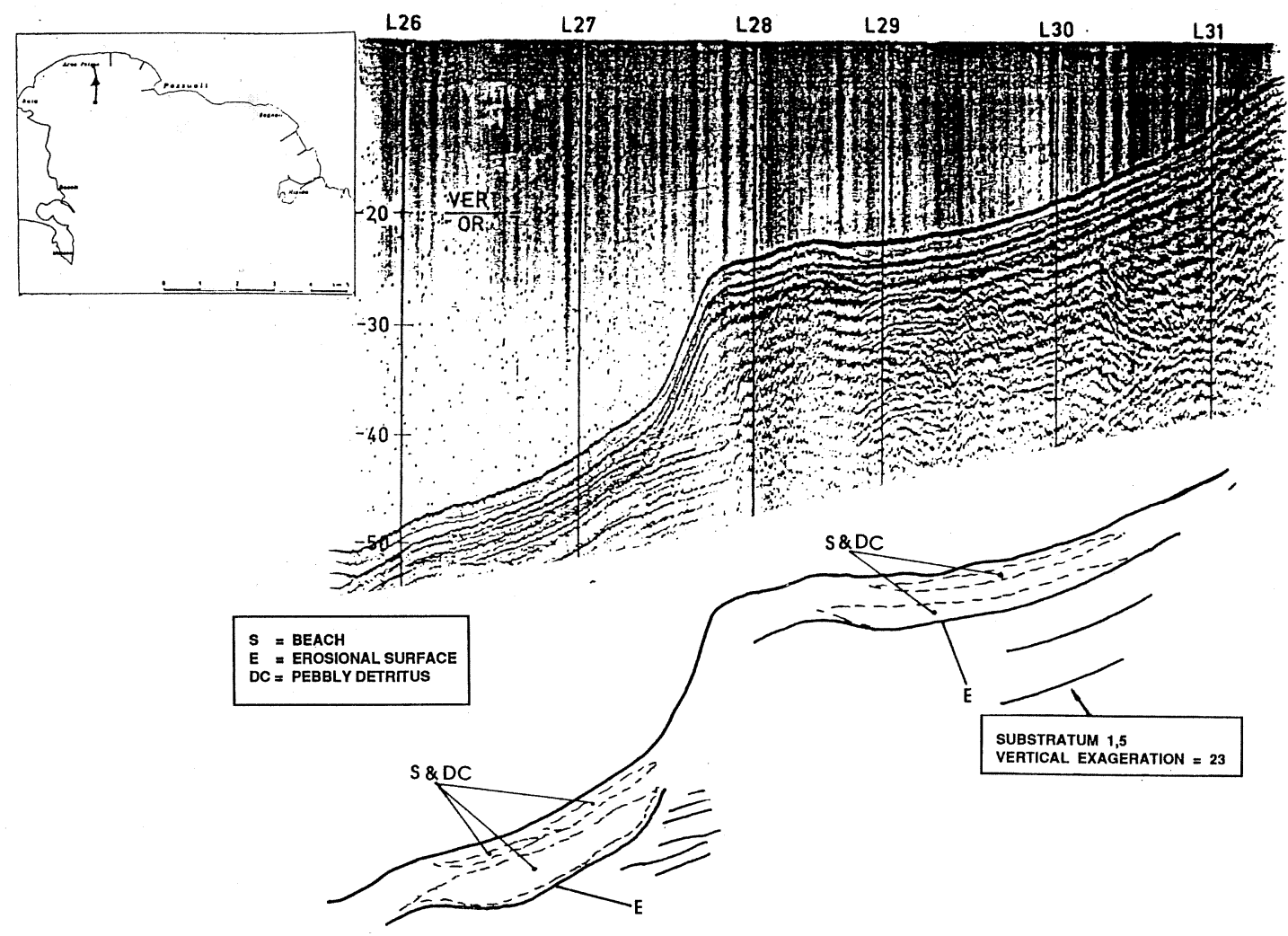

Fig. 5. This stratigraphy, corresponding to the route from L 26 to L31 beginning out at sea and going towards the coast (bathymetric 50 to $5 \mathrm{~m}$ ) is particularly interesting. Two terracings from -50 to -40 are evident; the first is from -25 and the second from $-12 \mathrm{~m}$. Uneven, pebbly material lies on top of both. Note underneath the more compact horizont: bed-rock a $1.5-2^{\circ}$ inclination (there is vertical deformation of 23 times versus the horizontal axis). The interpretation reflects Segre's Map (see text).

\section{Marine archaeological surveys using the Side Scan Sonar}

The Side Scan Sonar (SSS) is usually employed using a moving ship which tows the transducer («fish», i.e. a transmitter and receiver) at a working speed of 2 to 6 knots. It is therefore possible to investigate large areas in a relatively short time. The instrumentation is fully portable and can be used in small boats. The Side Scan Sonar acoustically records in real time an image of the sea bed which is comparable to aerial photographs or scanner images of land. The range of lateral coverage is inversely proportional to the outgoing frequency: a working frequency of $100 \mathrm{kHz}$ gives a maximum range of around $600 \mathrm{~m}(300 \mathrm{~m}$ on both sides of the track) and lower frequencies $(50 \mathrm{kHz})$ easily reach the $\mathrm{km}$ (Stefanon, 1985b).

We also used the SSS to investigate the presence of archaeological structures in shallow water (approximately $10 \mathrm{~m}$ ). It is, in actual fact, possible for divers to take direct readings using a camera or a video camera, the only limitation being that a wide-angle panorama of the situation cannot be obtained. However, difficulties can also arise in shallow water due to 


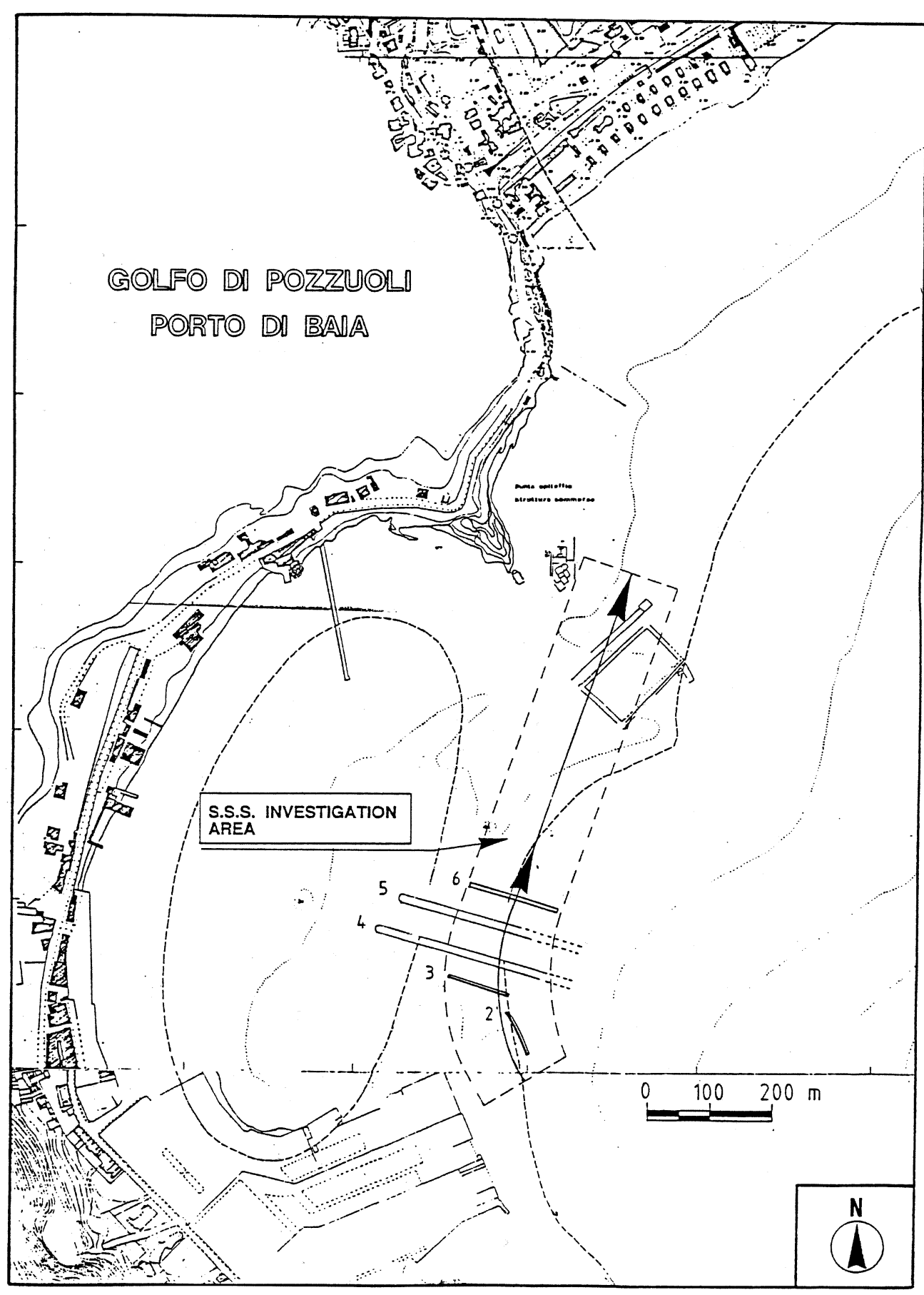

Fig. 6. Side Scan Sonar investigated area: Gulf of Pozzuoli after Camodeca, modified with structures 2-3-6. 


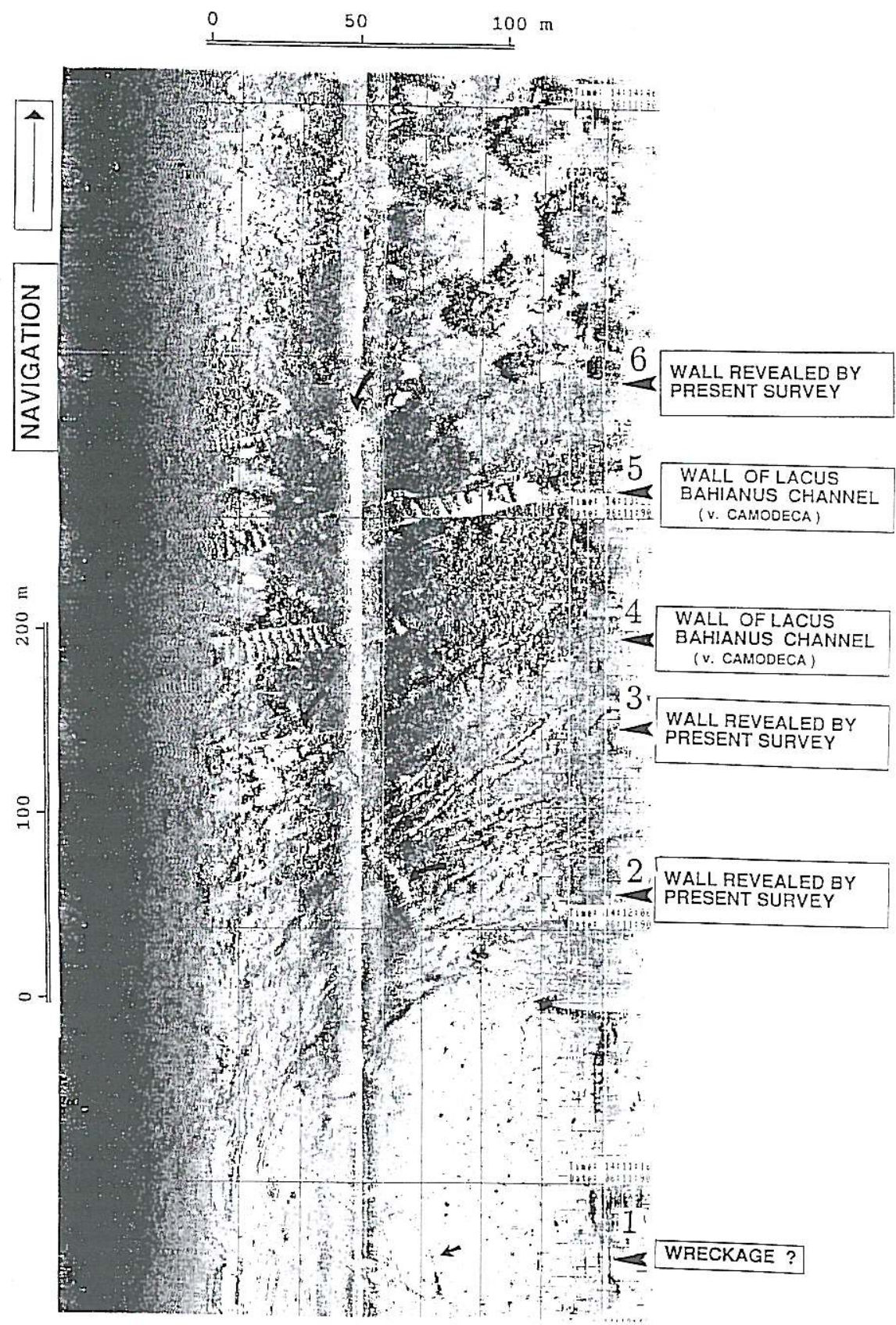

Fig. 7. Side Scan Sonar image of a strip of sea in front of the trading port of Baia running north-eastwards. 1) An outline can be seen in the depression suggesting a ship wreck just emerging from the sea bed; 4) and 5) are images of the two impressive walls of the access canal to the Lacuus Baianus, (Camodeca, 1987); 2 ) and 3) are wall structures unknown to bibliographies and their position would seem to indicate that they were used at a different period of time to (4) and (5) as they correspond probably to a different sea level. 


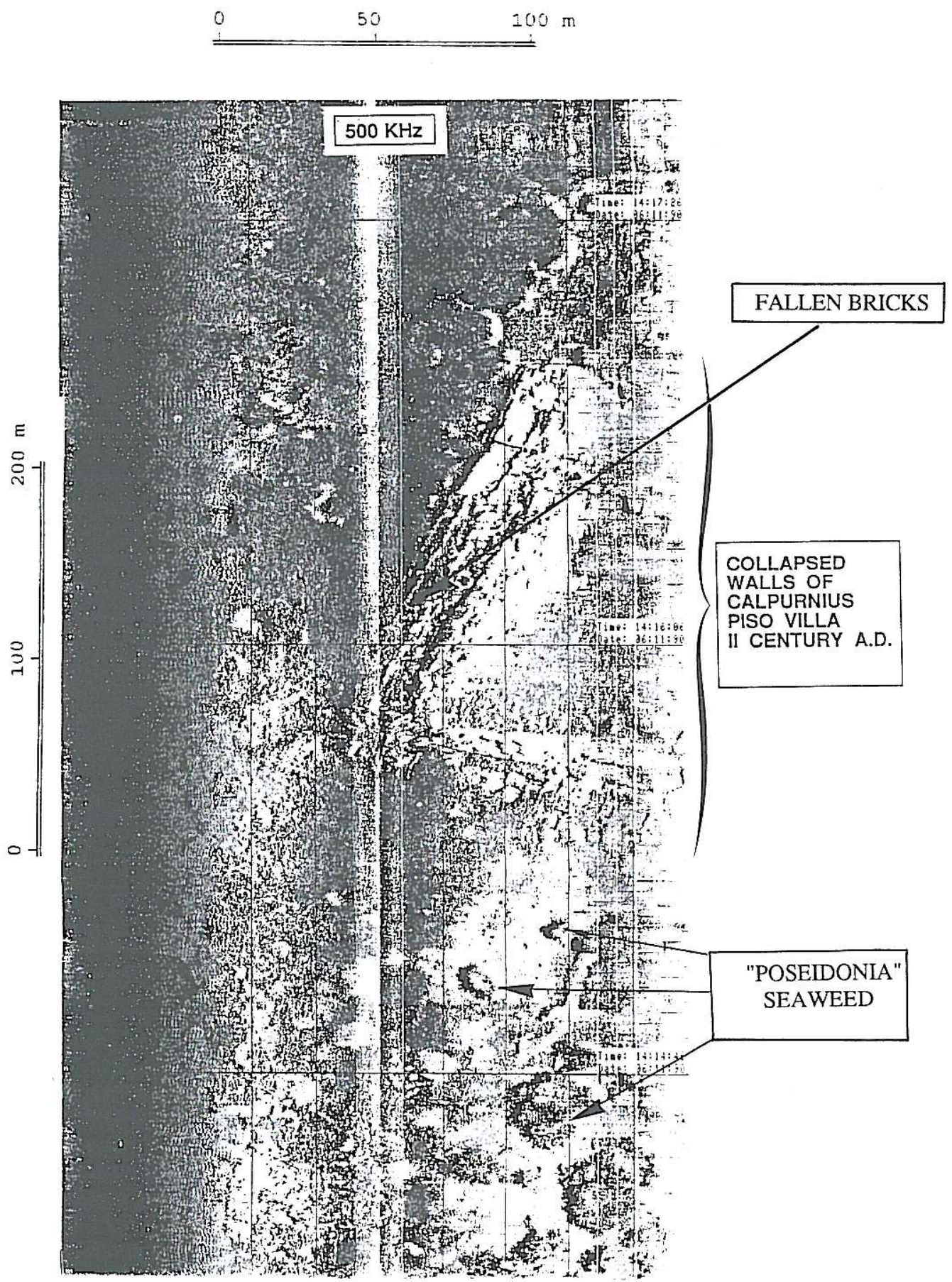

Fig. 8. Side Scan Sonar image of a part of Calpurnio Pisone's villa in the area of water opposite Epitaffio Head. 
murkiness and to the presence of lightweight mud on the sea bed. This does not occur with SSS.

SSS allows the sea bed to be explored in 100,150 and $200 \mathrm{~m}$ wide strips of unlimited length and with a covering speed of over $10000 \mathrm{~m}^{2}$ per first minute. The recordings can be read simply and almost immediately as will be demonstrated in the examples below.

We carried out a brief trial run of the SSS KLEIN (double frequency, $100-500 \mathrm{kHz}$ ) in the port area of Baia and Epitaffio Head. Exploring with a double frequency has the added advantage of being able to penetrate slightly beneath the underwater vegetation and the muddy blanket on the sea bed using the lowest frequency, but the highest frequency of 500 $\mathrm{kHz}$ produces more accurate readings. The recording strips shown in figs. 7 and 8 repre- sent the acoustic images which correspond to a working frequency $500 \mathrm{kHz}$; the theoretical resolution power is:

T. RES. POW. $\approx$ WAVELENGTH $\approx$ Velocity of Sound/Frequency $\approx(1.5 \mathrm{~km} / \mathrm{s}) /(500 \mathrm{kHz})=$ $3 \cdot 10^{-3} \mathrm{~m}$.

The recordings in figs. 7 and 8 were obtained along a route starting from the area facing the Baia Castle and ending around Epitaffio Head, also fig. 6. The sea beds explored lie at a depth of approximately $-10 \mathrm{~m}$.

The recording in fig. 7 shows part of the route running parallel to the coast in front of Baia Port (proceeding north eastwards). The first part of the recording gives evidence of a depression - the clear zone in the recording and in the middle there is a trace (mark 1)

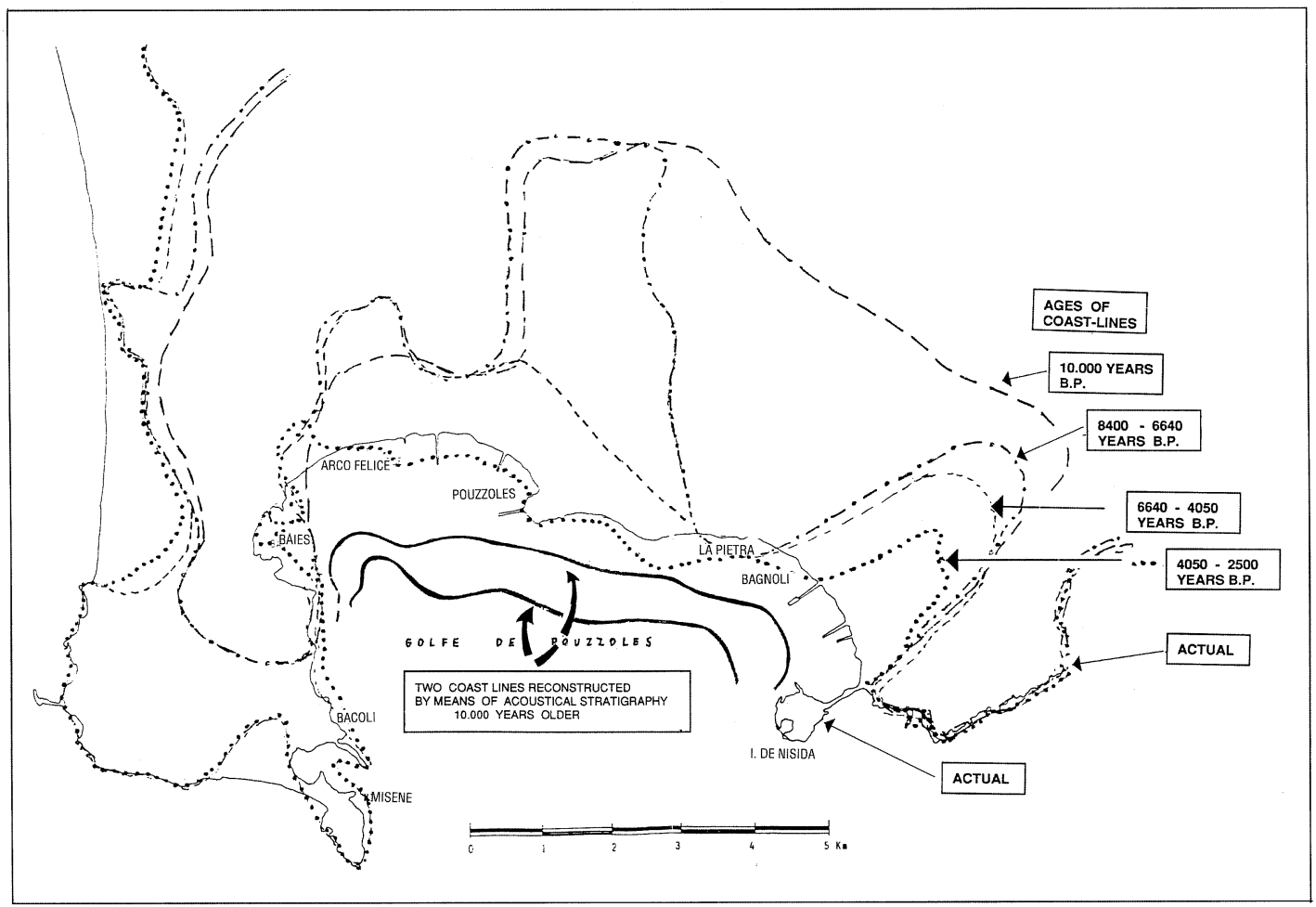

Fig. 9. A probable evolution of the Phlegraean coastline in the last 10000 years (after Albore Livadie, 1986, modified). 
which looks like a sunken ship, approximately $20 \mathrm{~m}$ long, half covered with muddy sand. At the end of this depression, corresponding to mark 2, there is a sort of wall which lies semitransversally compared to the route. Running perpendicularly to this wall lie tracks almost certainly caused by the dragging of anchors along the sea bed, since merchant ships dock near this area. Moving along, several impressive wall structures corresponding to $3,4,5,6$ are noted, and in particular numbers 4 and 5 . They correspond to the walled sides of the access canal to the Lacuus Baianus, dating from Roman times (Camodeca, 1987). The traces in 2, 3 and 6 do not appear to have been noticed by previous authors (see also fig. 6). In the route shown in fig. 8, which was approximately $300 \mathrm{~m}$ long and took $3 \mathrm{~min}$ to cover, a portion of the ruins of Calpurnio Pisone's villa, dating from the Roman Empire, was clearly visible. Close inspection showed the walls which were still standing were less than one metre tall. The resolution power of the instrument was even able to pick up the bricks which had fallen away and were lying on the sea bed.

\section{Conclusions}

The results obtained in this brief geophysical survey demonstrate the immense value of this type of sedimentological and evolutionary research in volcanic areas with the following phenomena: the deposits of eruptive products above and below water; upward and downward bradyseismic phenomena; massive erosions and collapses of various materials due to wave action. Geophysical methodologies are also able to discover anthropical structures and pick up detailed readings from them in a quick, direct and total manner, and are therefore useful for underwater archaeology. Marine geophysical surveys make continual spatial distribution data available, which are not easily obtainable on land. Defining the physical evolution of marine-continental-marine environments makes it possible to define the relationship between them and the presence of anthropical settlements.

A probable evolution of Phlegrean Field coastline in the last 10000 years is showed in fig. 9, merged with archaelogical lines of the C. Albore Livadie map (Albore Livadie, 1986).

\section{REFERENCES}

Albore Livadie, C. (1986): Considerations sur l'Homme prehistorique et son environnement dans le territoire phlegreen, Tremblements de Terre, Eruptions Volcaniques et Vie des Hommes dans la Campanie Antique, Centre Jean Berard-Napoli, 189-205.

Camodeca, G. (1987): Le Antichità di Pozzuoli, la ripa puteolana ed i resti sommersi del Portus Iulius, Riv. Puteoli, published by Gaetano Macchiaroli.

Luongo, G., E. Cubellis, F. Obrizzo and S.M. PetrazZUOLI (1991): The mechanics of the Campi Flegrei resurgent caldera - a model, Journal of Volcanology and Geothermal Research, 45, 161-172.

Pescatore, T., G. Diplomatico, M.R. Senatore, F. Tramutoli and L. Mirabile (1984): Contributi allo studio del Golfo di Pozzuoli: aspetti stratigrafici e strutturali, Mem. Soc. Geol. It., 149, 151-159.

Segre, A. (1972): La Carta Batimetrica del Golfo di Pozzuoli, Istituto Idrografico della Marina, Genova.

STEFANON, A. (1985a): Marine sedimentology through modern acoustical methods: II. Uniboom, Bollettino di Oceanologia Teorica ed Applicata, 2, 113-119.

Stefanon, A. (1985b): Marine sedimentology through modern acoustical methods: I. Side Scan Sonar, Bollettino di Oceanologia Teorica ed Applicata, 3 (1), 3-38. 